\title{
Developing Higher Level Thinking in Sexuality Education for Young People
}

\author{
Juliette D. G. Goldman
}

Griffith University

\begin{abstract}
Quality sex education for young people is crucial for promoting the development of their sexual knowledge, maturity, self-confidence, communication skills, and well-rounded personalities. However, much sex education appears to be anchored in Bloom's lowest levels of thinking namely Remembering, Comprehension and some in Application. Bloom's top three levels namely Analysis, Evaluation and Creating, exhibit the sorts of thinking that a meaningful adulthood requires, especially in all kinds of human relationships, and in personal management skills. So, helping to elevate young people's thinking skills to these higher levels may assist this development. In order to help young people develop higher level thinking skills in sexuality education, a variety of educational activities using Bloom's Revised Taxonomy are suggested here to guide the teacher and/or parent.
\end{abstract}

Keywords: sexuality education, Bloom's taxonomy, higher order thinking, sexual knowledge, quality in education

\section{Introduction}

Today's generation of young people are growing up in a world that is far more overtly sexualised than that experienced by previous generations. Young people today have lived from babyhood onwards with ubiquitous sexual images from a variety of sources including the media such as movies, TV, music, video clips, computer games, Internet, billboards and a variety of magazines. As well, modern everyday language is replete with sexual expletives and references, as is much modern clothing and personal image construction (See Klein, 2000). Many parents and educators are aware of this increased, overt, and also covert, sexualisation, and address sexuality education for young people using relevant and appropriate informative approaches (Blake, 2002; Goldman, 2000).

Sexuality constitutes just one facet in the development of all humans, and is a normal part of being human (Berger, 1998; Erikson, 
1963). All humans are sexual not only from birth but from when they were developing in the womb, and it is part of us from conception to death (See Goldman \& Bradley, 2004). Thus, with such an enduring part of our being, any knowledge and understanding we can gain about it will undoubtedly be self-enhancing and personally rewarding, resulting in an increased quality of life for all, through, particularly, improved personal understanding and enhanced inter-personal relationships (Blake, 2002; Goldman \& Bradley, 2001). Our need for enhanced sexuality information and sexual understanding grows as we develop (Goldman \& Goldman, 1981a, 1981b,1982; Goldman \& Bradley, 2004).

The education of any young person is incomplete unless he or she understands human sexuality (Goldman \& Goldman, 1988a). Within the human lifecycle, puberty is a time of accelerated physical, sexual, psychological and social changes for young people, while menopause and andropause are times of modification. The provision of sexual knowledge, skills, attitudes and values over the lifecycle is advantageous for well-rounded developmental growth (Goldman \&Bradley, 2001), In contrast, sexual ignorance can be disastrous and result in unwanted pregnancies, rape, mutilations, sexually transmitted infections (STIs) such as HIV/AIDS, child and adult sexual abuse, and unhealthy attitudes to human sexuality at any age (See Goldman, 2005; Goldman \& Goldman, 1988b). In fact, there is an increasing demand for sexual health to be seen as a basic human right (Coleman, 1999/2000).

\section{A Definition of Sexuality Education}

One of the most comprehensive definitions of sexuality education identifies it as:

a lifelong process of acquiring information and forming attitudes, beliefs, and values about identity, relationships, and intimacy. It encompasses sexual development, reproductive health, interpersonal relationships, affection, intimacy, body image, and gender roles. Sexuality education addresses the biological, sociocultural, psychological and spiritual dimensions of sexuality from 1) the cognitive domain, 2) the affective domain, and 3) the behavioural domain, including the skills to communicate effectively and make responsible decisions (Haffner, 1990: 2).

That is, sexuality education is conceptualised as broad, relevant, multi-faceted, contexualised and relevant across an individual's lifecycle. Sexuality programs that focus on information only are inadequate as they do not assist to develop healthy attitudes or the necessary skills to act upon that information (Gourlay, 1986). McCann (1999: 24) concurs and suggests that sexuality programs should deal 
with broader issues of 'sexuality, self-acceptance, body image, peer relationships, parent-child communication, sexual orientation, and the myriad of social and emotional issues'. Therefore, in order to be holistic, sexuality education needs to encompass physical, biological, psychological, socio-cultural, economic, ethical and moral dimensions.

There will always be a need for sexuality education (See Maddock, 1997). To date, sexuality education for young people has essentially been formal through school lessons, textbooks, or family, or informal through peer information which is frequently inaccurate or obscure (Goldman \& Goldman, 1981a, 1981b). Levitan (2000, 92) notes that:

Few school systems have ever truly implemented comprehensive health education for grades K-12, where students not only get information but also have the opportunity to examine how their belief systems impact their behaviour. And what has been labelled sexuality education has too often been heavily skewed toward the safe topics of anatomy and physiology of the reproductive system, pregnancy and childbirth, and sexually transmitted diseases.

Gourlay (1996) says that he personally had only approximately five hours of formal sexuality education over his 13 years at school in Australia. Considering that humans are living to an average of 80 years, five hours of sexuality education is inadequate as a preparation for a quality long life, and more so for young people who may receive even fewer hours than that.

\section{Goals of Sexuality Education}

A comprehensive sexuality education program for young people should have four main goals:

- to provide accurate information about human sexuality;

- to provide an opportunity to develop and understand one's values, attitudes, and beliefs about sexuality;

- to help develop relationships and interpersonal skills; and

- to help exercise responsibility regarding sexual relationships.

These include addressing abstinence, pressures to become prematurely involved in sexual intercourse, and the use of contraception and other sexual health measures (SIECUS, 1999: 29). All of these would constitute an appropriate basis for on-going sexuality education for young people (See also Blake, 2002).

Sexuality education programs should be appropriate to the individual's developmental level and should include analysis of issues such as communication, decision-making skills, friendships, family rela- 
tionships and self-esteem (SIECUS, 1999, 29; see also Amin, 2000; Blake, 2002; Goldman and Goldman 1981a, 1981b). Historically, there has been an increase in sexual encounters at a younger age, and the most recent Australian data (Australian Study of Health and Relationships, 2003) found the average age of first sexual intercourse has decreased to 16 years. It appears that every cohort is persuaded by various sources, including the fashion industry, to exhibit their sexuality in more overt ways than ever before. Self-managed sexual knowledge and behaviour is very important for life-long health (Blake, 2002), and supports the concept of sexual citizenship (West, 1999), that is, the sexually responsible citizen who has sexually responsible behaviour.

So the question is, how early should sexuality education begin? Many parents and sexuality educators, who are cognisant of the negative consequences for young people of sexual ignorance, believe it is never too early to provide children with nascent sexuality education. In fact Goldman and Goldman (1982) in their ground-breaking research on children's sexual cognition in the USA, Canada, UK, Sweden and Australia found that children as young as 5 years are able to grasp basic sexuality understandings about themselves, the other sex (a more appropriate term than opposite sex), relationships and roles, having babies, not having babies or contraception, and an appropriate accompanying vocabulary to aid their sexual conceptualisation.

In terms of young people's development, it has been found that, since the 19th century, puberty has been occurring earlier (see Tanner, 1978). The average age of reaching puberty for girls is about 12.3 years and for boys about 13.3 years (Goldman \& Goldman, 1982) which means that some will reach it sooner. For example, endocrinologists have observed 8 year-old girls exhibiting signs of puberty (See The Associated Press, 2001) and suggest that younger puberty is becoming the norm. Further, a study in the UK (Bristol University Institute of Child Health, 2001) found that one in six girls in Britain is reaching puberty by eight years of age. A number of theories have been promulgated to explain this, including young people's access, since babyhood, to enhanced nutrition and better health, less or nonexistent arduous physical work such as down in the coal mines, combined with living in a sexualised society with ubiquitous sexual role models for example in pop music videos.

One of the attendant difficulties for young people, especially girls, with precocious puberty is that their physical appearance may be disjunctive from their mental, emotional and knowledge development. Durham (1998:389) addressed sexual precocity as 'tensions that cen- 
tre around sexual decision-making versus sexual signification via costuming, cosmetics and body image', and that the representation of sexuality 'parallels socio-cultural nouns of contradiction and antilogy in the characteristics of girls' desire'. Here, particularly, there is an exigent need for, not just for these girls, but also for all young people, to have an informed knowledge and understanding of their bodies and their developing sexuality earlier than previously thought.

\section{Changing Educational Contexts}

In this new millennium, change seems endemic. Educational theory and practice are changing (See Pateman, Grunbaum, \& Kahn, 1999). So too are schools. This has been directly attributable to the commodification of education as a saleable substance, the evolution of new economies and workplaces, the changing and blurring of school/home/work relationships, the fashionableness of home-based education, world-wide learning, and the multifunctional residence (Gibbon et al., 1994). Greater educational flexibility means curricula are becoming more personalised, technological-based (see West, 1999), and focused towards individual learning at students' own pace and according to personal interests.

One of the main changes in education is the realisation that young people's learning can take place at any time of the day or night rather than in predetermined school periods, thus heralding the demise of timetabled learning. Education will become increasingly more individualised, self-determined, self-focused, and self-directed. 'Information is no longer power, it's interpretation of information that is important' (Sorrell, 2000). This means that finding, accessing, and using information will be power (e.g. such as using search engines). It is the operationalisation of information that has become important, not the 'searching and gathering'. That is, in terms of Bloom's levels, it is the Analysis, and Synthesis, or higher level order thinking skills, that are essential for young people.

\section{Productive Pedagogies}

Education Queensland has introduced this theoretical framework embedded in the New Basics Project for teachers to use when reflecting and planning effective teaching and learning experiences for school students (Education Queensland, 2003a, 2003b). Stemming from the Queensland School Reform Longitudinal Study, 20 teaching strategies are identified to promote and improve student outcomes. The four main strategies of Productive Pedagogies promote intellectual quality, global and local connectedness, a supportive classroom environment, and recognition of difference. This framework supports the varying learning styles, approaches, and backgrounds of students, 
and allows teachers to develop strategies to provide opportunities to develop the necessary skills for students' future. In the category Intellectual Quality, Bloom's Taxonomy of levels of thinking is identified as an avenue to enhance students' learning (See Education Queensland, 2003a, 2003b).

\section{Bloom's Taxonomy and the Revised Taxonomy}

Bloom's Taxonomy is a hierarchical classification of cognitive structures designed as part of a study involving learning processes in the three areas Cognitive, Affective and Psychomotor. Bloom's classification and ordering of thinking skills from lower to higher, is frequently used by educators, to develop learning experiences for students (See Education Queensland, 2003b). The lowest level is Knowledge or the ability to remember information. The next level is Comprehension or the ability to understand meaning, followed by Application or the ability to apply or use a concept in a new situation. The fourth level is Analysis where a student can separate concepts into parts. This is followed by Evaluation where the student can make a judgement about the value of ideas and their connections. Finally, the highest level is Creativity, where disparate elements are explored and gathered into a newly conceived coherent whole which produces an intellectual advancement (See Frangenheim 1998, 2003).

In the revised version of the six levels of Bloom's taxonomy, (see table 1 in the appendix) Anderson and Krathwohl (2001) add four Knowledge dimensions, namely Factual Knowledge, Conceptual Knowledge, Procedural Knowledge and Metacognitive Knowledge.

These categories are assumed to lie along a continuum from concrete (Factual) to abstract (Metacognitive). The Conceptual and Procedural categories overlap in terms of abstractness, with some procedural knowledge being more concrete than the most abstract conceptual knowledge (Anderson \& Krathwohl, 2001: 5).

This arrangement allows teachers the opportunity to construct alignment, or the degree of correspondence, among which cells are identified for the three aspects educational objectives, educational activities, and assessment (Anderson \& Krathwohl, 2001: 250-256). Strong alignment will occur if the three are located in the same cell, weaker alignment if a cell contains two of them, and weakest alignment if a cell contains only one (Anderson \& Krathwohl, 2001: 10).

\section{Bloom's Levels and Sexuality}

In response to this enhanced approach to student learning, it is appropriate, then, to see how Bloom's revised levels may be applied to a selection of instructional activities on sexuality education. Bloom's 
Revised Taxonomy of Levels of Thinking may be applied to some sexuality education. Such an application will be useful for educators and parents to help ensure that their young people do not persist in low level thinking, but are encouraged to rise to higher, more mature levels of thinking, in this important area. In table 2 (see appendix), the first word in brackets is one of the six Bloom's Cognitive Process Dimension, then the second word is one of the four Knowledge Dimensions (See Anderson \& Krathwohl, 2001: 5).

\section{Higher Level Thinking in Sexuality Education}

In order to assist young people to develop higher level thinking skills in sexuality, the variety of instructional activities suggested in Table 2 indicates how the teacher and/or parent can help to develop their child's learning on Bloom's levels. Currently much sexuality education is anchored in Factual Knowledge in the two lowest levels of Knowledge and Comprehension, and some in Application. However, there appear to be few activities for young people to raise their thinking levels to the top three levels of Analysis, Evaluation and Creating in tandem with Conceptual, Procedural and Metacognitive Knowledge. These three upper Levels and Dimensions exhibit the sorts of thinking that a meaningful adulthood requires, especially in general human relationships, sexual relationships, and in personal management skills. So, helping to elevate young people's thinking skills to the higher levels will prepare them well for their adulthood (See also Blake, 2002). In the light of Productive Pedagogies' use of Bloom's Thinking levels, then, the goals of a comprehensive sexuality education mentioned earlier, may need to be adjusted to also include: to provide students with assistance to achieve not only a framework for thinking in Bloom's levels to Analysis, Evaluation and Creating but also in identifying at the upper Knowledge Dimensions of Conceptual, Procedural and Metacognitive Knowledge.

\section{Conclusion}

The elevation and growth of young people's thinking skills about sexuality will enhance their sexual knowledge, personal development, self-concept, self-esteem, maturity, and personal decision-making skills. They will benefit by becoming more analytical, evaluative and creative, more competent in handling Procedural knowledge and Metacognitive knowledge, more aware and more self-confident about themselves and their enhanced social relationships, and concurrently will develop greater personal self-management. Higher-order sexuality education for young people will enhance their lifelong learning in helping to develop well-adjusted children into well-adjusted teenagers, and well-adjusted teenagers into well-adjusted adults. Such personal enhancements will benefit individuals and societies at 
large, thus enhancing their social capital (see Drielsma, 2000) resulting in an improved quality of life for everyone.

\section{References}

Amin, T. (2000 Students Need Better Sex Ed, [Accessed: 27 March 2000], URL:http://www.sxetc.org/librarylarticles/artOOW_130.asp

Anderson, L. W. \& Krathwohl, D. R. (ed.) (2001 A Taxonomy for Learning, Teaching and Assessing; A Revision of Bloom's Taxonomy Educational Objectives, New York: Longman.

Australian Study of Health and Relationships, (2003) Melbourne: La Trobe University.

Berger, K. S. (1998 The Developing Person Through the Lifespan, New York: Worth.

Blake, S. (2002) Sex and Relationships Education. A Step-by Step Guide for Teachers, Fulton: London.

Bristol University Institute of Child Health (2000 Children of the Nineties, Bristol, U.K.

Coleman, E. (1999/2000 A new sexual revolution in health, diversity, and rights. Siecus Report, New York; Dec 1999/Jan 2000, 28, 2: 4-8.

Drielsma, P. (2000) Hard living young brains for intimacy, Child Abuse Prevention Newsletter, National Child Protection Clearinghouse, The Australian Institute of Family Studies, 8, 2: 6-11.

Durham, M. G. (1998) Dilemmas of desire: Representations of adolescent sexuality in two teen magazines, Youth and Society, 29, 3: 369-389.

Education Queensland (2003a) [Accessed on-line 5 April 2003], URL:

http: /www.education.gld.gov.au/corporate/newbasics/html/pedagogies/pedagog.html

Education Queensland (2003b) [Accessed on-line 6 April 2003], URL: www.education.gld.gov.au/tal/tips/hot_topics/0617.htm

Erikson, E. H. (1963) Childhood and Society, New York: Norton.

Frangenheim, E (2003) Educators' Reflection Journal, Loganholme, Qld.; Rodin Educational Consultancy.

Frangenheim, E (1998) Reflections on Classroom Thinking Strategies, Practical strategies to encourage thinking in your classroom, Loganholme, Qld.; Rodin Educational Publishing.

Gibbon, M., et al., (1994) The New Production of Knowledge: the Dynamics of Science and Research in Contemporary Societies. London; Sage Publications.

Goldman, J. D. G. (2005) Student-teachers' learning about child sexual abuse strategies in Primary School: An exploratory study of Surface and Deep Learning, Sex Education. (forthcoming).

Goldman, J. D. G. (2000) Sexuality Education in the New Millennium. Keynote address. Paper presented at the 4th National Sexuality Conference, Hobart, Australia, 21-23 May.

Goldman, J. D. G. \& Bradley, G. L. (2004) Sexuality education for older people in the technological age, Australian Journal of Primary Health, 10, 1: 96-105.

Goldman, J. D. G. \& Bradley, G. L. (2001) Sexuality Education across the LifeCycle in the New Millennium. Sex Education, 1, 3: 175-218.

Goldman, R. J. \& Goldman, J. D. G. (1981a) Sources of Sex Information for Australia, English, North American and Swedish Children, The Journal of Psychology, 109: 97-108.

Goldman, R. J. \& Goldman, J. D. G. (1981b) What Children want to know about 
Sex and what they claim to receive in School: A Comparison of Australian with English, North American and Swedish Children. The Australian Science Teachers Journal. 27, 2: 61-69.

Goldman, R. J. \& Goldman, J. D. G. (1982) Children's Sexual Thinking. Henley, UK: Routledge \& Kegan Paul.

Goldman, R. J. \& Goldman, J. D. G. (1988a) Show Me Yours. Understanding Children's Sexuality. Melbourne: Penguin.

Goldman, R. J. \& Goldman, J. D. G. (1988b) The Prevalence and Nature of Child Sexual Abuse in Australia. Australian Journal of Sex, Marriage and the Family. 9, 2: 94-106.

Gourlay, P. (1996) If you Think Sexuality Education is Dangerous, Try Ignorance! - Sexuality Education: Critical Factors for Success. Box Hill, Australia: Family Planning Victoria.

Haffner, D. W. (1990) Towards a New Paradigm on Adolescent Sexual Health. Siecus Report. December 1992-January 1993.

Klein, M. (2000) Coming attractions: Sexual expression in the next decade. Siecus Report, New York. Dec 1999/Jan 2000. 28, 2: 9(6).

Levitan, J. (2000) Health and Sexuality Education in Schools: The Process of Social Change (Book Review). By Steven P. Ridini. Journal of Sex Research. Feb2000. 37, 1: 92.

Maddock, J. W. (1997) Sexuality Education: A History Lesson. In J. W. Maddock (ed), Sexuality Education in Postmodern and Professional Training Settings. New York: The Haworth Press.

McCann, S. (1999) Learning to feel good about yourself: Puberty education reconsidered. Siecus Report, New York. Aug/Sep 1999. 27, 6: 24(4).

Pateman, B. Grunbaum, J. \& Kahn, L. (1999) Voices from the Field -A Qualitative Analysis of Classroom, School, District, and State Health Education Policies and Programs. Journal of School Health. Sept. 69, 7: 258263.

SIECUS (Sex Information and Education Council of the Unites States). (1999) Issues and answers facts sheet on sexuality education. Siecus Report, New York. 27, 6: 29(5).

Sorrell, M. (2000) Trend of the World as We Know It . . . is American. The Australian. 8 February 2000, 27.

Tanner, J. M. (1978) Foetus into Man, Cambridge, Mass: Harvard University Press.

The Associated Press. (2001) Early Signs Of Puberty Evident. [Accessed online, Tuesday, 20 February 2001], URL:

http://www. intelihealth.com/IH/ihtlH/WSIHW000/333/22002/311408.html

West, J. (1999) (Not) talking about sex: Youth, identity and sexuality, Sociological Review, 47, 3: 525-547. 


\section{Appendix}

Table 1: Bloom's Revised taxonomy for learning, teaching and assessing

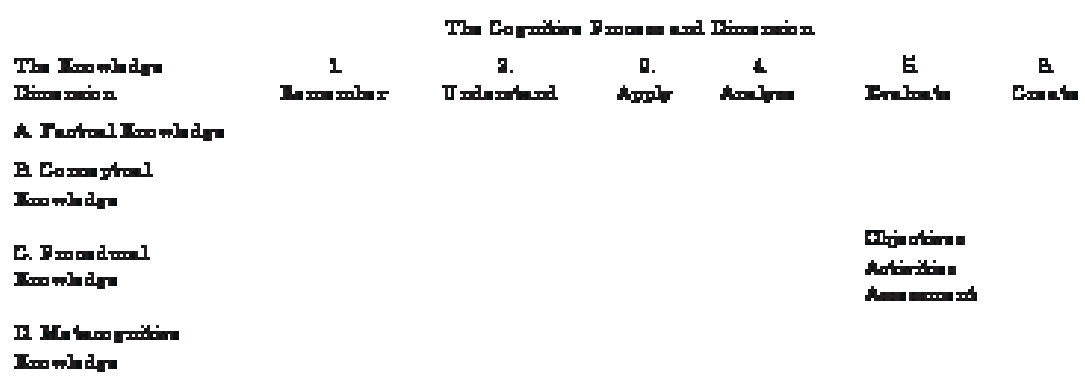

Table 2: Some examples of Bloom's Revised Taxonomy levels in sexuality activities for young people

Creating (highest level)

Designing, Procedural: Design an effective contraception for both sexes for the 21st century.

Complexity, Procedural: Explain as accurately and as detailed as you can, the complexity of the workings of the female and the male sexual system.

Elaborating, Procedural: Elaborate the principles of the human Hormone System.

Extrapolating, Procedural: If you were World Minister for Population, what would you do to achieve Zero Population Growth (ZPG).

Flexibility, Procedural: View the video "Plumpton High School Teenage Mothers ". If you were a teacher at that school, what educational of other changes could you make to school life to help the next cohort of teenagers avoid being teenage mothers and teenage fathers.

Forecasting, Conceptual: Predict on this 30 day calendar of a woman's cycle, when are her most fertile times.

Hypothesising, Procedural: What would happen to world population if a nonbreakable, free condom were invented?

Modifying, Procedural: If you were World Education Minister how would modify education curriculum to provide better inter-personal relationships education for all young people.

Organising, Procedural: If you were World Health Minister, how would you organise a group of specific countries to educate their next generation about HIV/AIDS?

Originality, Metacognitive : Create a video with at least 5 original suggestions, for young people on "How to improve my inter-personal relationships".

Planning, Procedural: Plan $a$ healthy and positive sex life for yourself.

Proposing, Procedural: Create an original proposal about how to minimise the number of teenage mothers and fathers in Australia.

Risk-taking, Procedural: Draw up a SWOT Analysis (Strengths, Weaknesses, 
Opportunities and Threats) of having unprotected sex for teenagers.

Synthesising, Metacognitive: Analyse all the factors that influence a young person's attitudes to sexuality, and synthesise it into a coherent whole with critical suggestions for improved sexuality education.

\section{Evaluation}

Arguing, Conceptual: Present an argument in support of better contraception use by Australians.

Assessing, Conceptual: Make an assessment using PMII (Plus, Minus, Interesting \& Investigate) about World Populationthat now exceeds 6 billion and rising.

Choosing, Conceptual: In a group, choose De Bono's 6 Hats to consider the problem of "How can people get along better together?"

Concluding, Conceptual: View the video "Plumpton High School Teenage Mothers". What can you conclude about the future life of those babies.

Deciding, Procedural: Choose one form of contraception. Decide on the advantages and disadvantages of each and compare those characteristics with those from three other students, and arrive at a conclusion about each.

Determining, Procedural: View the video "Plumpton High School Teenage Mothers". If you were the School Principal, determine what you could do to minimise the number of future teenage mothers.

Fudging, Conceptual: Use the "Looks Like, Sounds Like and Feels Like" chart for the concept "friendship". Discuss results with your group, and arrive at a judgement about the best sorts of friendship for you.

Justifying, Factual: Brainstorm a list of behaviours appropriate to when you meet someone new. Justify your list.

Prioritising, Procedural; (Related to Rating below) Based on the available evidence, prioritise this list of contraception types from most reliable to least reliable.

Rating, Conceptual: (Related to Prioritising above) Based on this evidence, rate the costs, personal, financial and other, of each of these forms of contraception.

Recommending, Procedural: Make 5 recommendations about how to respond appropriately to unwanted sexual pressure.

Selecting, Procedural: Select the Disadvantages and the Improvements you could make in response to any changing inter-personal relationships you are having eg with a teacher or peer, and analyse them.

\section{Analysis}

Arguing, Procedural: Prepare a comprehensive argument why it is advantageous for teenage girls not to become pregnant.

Analysing, Metacognitive: How do you understand your self-decalage. Analyse your self-perception in terms of being a wise friend.

Categorising: Categorise the different types of friendships you have in terms of their similarities and dissimilarities.

Comparing, Procedural: Compare the advantages and disadvantages of any five forms of contraception. 
Summarising, Conceptual: Summarise the role that the hormone Estrogen plays in the female body, and Testosterone in the male body.

Contrasting, Conceptual: Contrast the influence of drugs and alcohol compared to no drugs or alcohol on young people's lives.

Debating, Procedural: Have a class debate using correct debating rules on the topic " That current world population at more that 6 billion is excessive for this one globe".

Differentiating, Metacognitive: From all these students' questions in the Question Box, differentiate the most commonly asked questions, and the least asked questions. Explain why this might be so.

Discussing, Factual: Discuss what are the sources of advice and support available for young people today.

Distinguishing, Procedural: Distinguish the characteristics that differentiate a good relationship from other relationships

Examining, Metacognitive: Examine your feelings about growing up, being assertive and resisting peer pressure and stereotyping. What conclusions can you arrive at, to guide you in the future.

Explaining, Procedural: Explain the reasons for having protected sex.

Identifying, Metacognitive: Identify the muddy thinking in this statement "When girls say no they mean yes".

Investigating, Conceptual: Investigate what STIs (Sexually transmitted Infections) are, how they are contracted, how they are treated, and you can avoid them.

Separating, Metacognitive: Use "Think, Pair, Share" to make value separations in "What are my values about myself, my peers, my family, and my pets?"

\section{Application}

Applying, Metacognitive: Apply the principles of good parenting to the life of a child. Explain the consequences for both parents and child.

Calculating, Conceptual: Who can calculate the different parts of a woman's monthly cycle?

Compiling, Conceptual: Compile a list of STIs.

Completing, Conceptual: Complete this sentence "Masturbation is ..."

Constructing, Procedural: Who can construct the steps that occur in an ejaculation?

Demonstrating, Procedural: On this model of a female human body, demonstrate how a female Diaphragm works?

Extrapolating, Conceptual: If a couple have unprotected sex, what could be the consequences?

Illustrating, Procedural: On this diagram of a female body, identify her sexual organs, label and spell them accurately.

Inferring, Conceptual: From this blank diagram of a woman's Uterus, what can you infer about where she is in her monthly cycle?

Showing, Conceptual: Who can show me on this diagram one of the systems of the human body and how it works? 
Solving, Conceptual: What is a sexual problem you are unable to solve? Write it on a slip of paper and put it in the Question Box. Choose someone else's slip from the box and answer it.

Using, Procedural: Explain how women use a pregnancy test bought at a Supermarket or chemist.

\section{Comprehension}

Describing, Procedural: Describe the process of having periods.

Explaining, Procedural: Explain what a wet dream is.

Interpreting, Conceptual: Who can interpret what all these squiggly parts in the Testicles are for?

Outlining, Conceptual: Who can outline the birth process?

Paraphrasing, Conceptual: Who can paraphrase the occurrences during the 9 months of the gestation period of a baby?

Simple Summary, Conceptual: Who can give me a simple summary of the principles of effective contraception?

Translating, Factual: What does STI stand for and how is it related to HIV/AIDS?

Understanding, Conceptual: What do you understand the role of Seminal Fluid to be? Explain it?

Knowledge (lowest level)

Defining, Factual. What is your definition of a Uterus?

Describing, Factual: Describe the journey of a group of Sperm from where they start to their final destination.

Fluency, Factual: Tell us a story describing the journey of the ovum from where it starts in the body to its finaldestination.

Knowing, Factual: Who knows what this sexual organ is? (picture of an ovary releasing an ovum)

Labelling, Factual: Label accurately the different parts of the male and the female sexual systems.

Listing, Conceptual: List in correct order the organs where Sperm originate, what organs they pass, and where they end upif one type of contraception is used..

Locating, Factual: On this diagram of a woman's reproductive system, locate where a diaphragm is placed to be effective.

Memorising, Factual: Who has memorised all the blank name lines on these two diagrams of the male and female sexualsystems?

Naming, Factual: Name the glands and the sexual hormones they produce.

Remembering, Factual: Who can remember the name of the tube that joins the Uterus to near the Ovary?

Retelling, Procedural: Who can retell accurately about the development of a fertilised Ovum in a woman's body?

Stating, Factual: Who can state the accurate name of this organ in the male? (Vas Deferens) 